\title{
Origin of Cell Populations After Bone Marrow Transplantation Analysis Using DNA Sequence Polymorphisms
}

\author{
David Ginsburg, Joseph H. Antin, Brian R. Smith, Stuart H. Orkin, and Joel M. Rappeport \\ Division of Hematology, Brigham and Women's Hospital; Division of Hematology/Oncology, Children's Hospital Medical Center; \\ Division of Pediatric Oncology, Dana-Farber Cancer Institute; Departments of Medicine and Pediatrics, \\ Harvard Medical School, Boston, Massachusetts 02115
}

\begin{abstract}
After successful bone marrow transplantation, patient hematopoietic and lymphoid cells are replaced by cells derived from the donor marrow. To document and characterize successful engraftment, host and donor cells must be distinguished from each other. We have used DNA sequence polymorphism analysis to determine reliably the host or donor origin of posttransplant cell populations. Using a selected panel of six cloned DNA probes and associated sequence polymorphisms, at least one marker capable of distinguishing between a patient and his sibling donor can be detected in over $95 \%$ of cases. Posttransplant patient peripheral leukocytes were examined by DNA restriction enzyme digestion and blot hybridization analysis. We have studied 18 patients at times varying from 13 to 1,365 d after marrow transplantation. Mixed lymphohematopoietic chimerism was detected in 3 patients, with full engraftment documented in 15 . One patient with severe combined immunodeficiency syndrome was demonstrated to have $T$ cells of purely donor origin, with granulocytes and $B$ cells remaining of host origin. Posttransplant leukemic relapse was studied in one patient and shown to be of host origin. DNA analysis was of particular clinical value in three cases where failure of engraftment or graft loss was suspected. In two of the three cases, full engraftment was demonstrated and in the third mixed lymphohematopoietic chimerism was detected. DNA sequence polymorphism analysis provides a powerful tool for the documentation of engraftment after bone marrow transplantation, for the evaluation of posttransplant lymphoma or leukemic relapse, and for the comprehensive study of mixed hematopoietic and lymphoid chimeric states.
\end{abstract}

\section{Introduction}

Bone marrow transplantation involves the replacement of patient or "host" hematopoietic and lymphoid cells with those of a healthy donor (1). To document and characterize successful engraftment after transplantation, cells of host and donor origin must be distinguished from each other. Methods that

A preliminary report of this work was presented at the Plenary Session of the 25th Meeting of the American Society of Hematology, in December 1983.

Address reprint requests to Dr. Ginsburg, Division of Hematology, Brigham and Women's Hospital, Boston, MA 02115.

Received for publication 28 June 1984 and in revised form 19 September 1984.

J. Clin. Invest.

(c) The American Society for Clinical Investigation, Inc.

0021-9738/85/02/0596/08 $\$ 1.00$

Volume 75, February 1985, 596-603 have been used for this purpose include: erythrocyte antigen typing (2-6), HLA-typing (6), leukocyte isoenzymes (2-4), immunoglobulin isotypes $(4,7)$, Barr and Y-body analysis (812), and karyotyping techniques (3-6, 9, 11, 13-15). Cytogenetic techniques are only rarely applicable where patient and donor are of the same sex. Furthermore, karyotype analysis requires cell division and thus is restricted to proliferating cell populations. Erythrocyte antigen and immunoglobulin isotype studies are obscured by transfusion and are rarely useful in the first few months after transplantation. In addition these latter techniques each provide information relevant to only one cell line. HLA-typing only applies when the patient and donor are not HLA-identical. Despite these limitations, occasional cases of mixed hematopoietic chimerism have been documented (3, 5, 11, 14, 16, 17). Engraftment, however, is frequently determined based solely on the rise in peripheral blood counts at the expected time after marrow transplantation.

DNA sequence polymorphisms are neutral variations in DNA sequence present throughout the genome, which can often be detected by restriction enzyme digestion and blot hybridization analysis. Most well-described DNA sequence polymorphisms involve single nucleotide changes, or small insertions or deletions, which result in the presence or absence of a particular restriction enzyme recognition site (18-21). In another type of polymorphism, a large segment of DNA of unknown function varies widely in length among individuals $(22,23)$. Both types of sequence differences and resulting varying DNA restriction fragment lengths are inherited in Mendelian fashion. The end result is a unique band pattern on blot hybridization analysis that can often clearly distinguish between two individuals.

An increasing number of such sequence polymorphisms have been described involving portions of several different chromosomes (18-24). These genetic markers have been widely used in the study and prenatal diagnosis of the hemoglobinopathies $(18,19,25,26)$, and more recently in the analysis of other disorders $(19,20,23)$.

This study describes the use of DNA sequence polymorphisms to develop a generally applicable and sensitive method to distinguish the cells of host and donor origin in patients after bone marrow transplantation. We demonstrate the utility of this technique for the documentation of engraftment and for the detection of mixed hematopoietic and lymphoid chimerism.

\section{Methods}

Patients studied. Patients and donors admitted to the bone marrow transplantation service of the Brigham and Women's Hospital and Children's Hospital, Boston, MA, between May 1983 and December 1983 were prospectively studied. Selected patients transplanted before May 1983 were also evaluated. Diagnoses and the day of study after 
Table I. Patients Examined Post-BMT

\begin{tabular}{lllll}
\hline UPN & Diagnosis & Preparation & $\begin{array}{l}\text { Day of study } \\
\text { (post-BMT) }\end{array}$ & Findings \\
\hline 140 & ALL & CTX/TBI & $27,50,175$ & Complete engraftment* \\
153 & ALL & CTX/TBI & $25,45,94$ & Mixed lympho-hematopoietic chimerism \\
075 & AML & CTX/TBI & 1365 & Complete engraftment \\
149 & AML & CTX/TBI & 33,65 & Complete engraftment \\
150 & AML & CTX/TBI & 34 & Complete engraftment \\
151 & AML/RDA & CTX/TBI & 13,20 & Complete engraftment \\
152 & AML & CTX/TBI & 27 & Complete engraftment \\
134 & CML & CTX/TBI & 190,288 & Complete engraftment \\
144 & CML & CTX/TBI & 27,120 & Complete engraftment \\
$147 \mathrm{H}$ & JCML & CTX/ATS/PC/TBI & 66 & Complete engraftment \\
146 & AM & CTX/TBI & 74 & Mixed lympho-hematopoietic chimerism \\
XXX & AA & CTX & 610 & Complete engraftment \\
087 & AA & CTX/ATS/PC & $1,125,1,275$ & Complete engraftment \\
136 & AA & CTX/ATS/PC & 94 & Complete engraftment \\
145 & AA & CTX/ATS/PC & 28,108 & Complete engraftment \\
139 & WA & CTX/ATS/TBI & 114 & Lymphoid chimerism; granulocytes- \\
$128 \mathrm{H}$ & SCIDS & CTX/ATS & $345,390,430$ & host \\
& & & & B cells-host \\
& & & & T cells-donor \\
$138 \mathrm{H}$ & SCIDS & CTX/ATS/BU & 33 & Complete engraftment \\
& & & &
\end{tabular}

Abbreviations: AA, aplastic anemia; AM, acute myelofibrosis; BU, busulfan; CTX, cyclophosphamide; "H" denotes HLA haploidentical donor; JCML, juvenile chronic myelogenous leukemia; PC, procarbazine; RDA, refractory dysmyelopoietic anemia; WA, Wiskott-Aldrich syndrome. * "Complete engraftment" denotes that all examined peripheral blood cells were of donor origin by DNA analysis. ‡ Patient UPN XXX underwent bone marrow transplantation at the Fred Hutchinson Cancer Center, Seattle, WA.

transplant are listed in Table I. Preparative chemoradiation therapy varied according to the underlying disease and is also outlined in Table I. Donor selection, conditioning regimens, transplantation procedure, and posttransplant management have been previously described $(1,3$, $6,27)$. Unique patient number (UPN) 1075 and 134 received $850 \mathrm{rad}$ of single fraction total body irradiation (TBI). Patients with chronic myelogenous leukemia (CML) or acute lymphoblastic leukemia (ALL) received 1,200 rad of TBI in six 200-rad fractions. All other irradiated patients received 1,080 rad in six 180-rad fractions. All radiation was administered at $5 \mathrm{rad} / \mathrm{min}$. Seven patients had $T$ cell depletion of marrow by monoclonal antibody and complement prior to infusion. Four donor marrows were treated with the monoclonal antibody $\mathrm{T} 12$ (UPN 128H, 138H, 144, 147H) (6) and three were treated with the monoclonal antibody Leu 1 (Becton-Dickinson Co., Inc., Mountainview, CA) (UPN 151, 152, 153, unpublished data). Informed consent was obtained from all patients and donors according to the institutional review board guidelines.

Preparation of genomic DNA samples. Peripheral blood specimens from patients before transplantation and donors (as well as parents in selected cases) were collected in 10\% acid-citrate-dextrose. High molecular weight DNA was prepared by standard techniques either from dextran sedimented leukocytes (28) or isolated nuclei separated by centrifugation following Triton X-100 solubilization (23). When pre-

1. Abbreviations used in this paper: ALL, acute lymphoblastic leukemia; AT3, antithrombin III; ATS, antithymocyte serum; CFU-C, mycloid colony-forming unit; CML, chronic myelogenous leukemia; EBV, Epstein-Barr virus; FACS, fluorescene-activated cell sorter; FITC, fluorescein isothiocyanate; GVHD, graft versus host disease; kb, kilobase; PGK, phosphoglycerate kinase; SCIDS, severe combined immunodeficiency syndrome; TBI, total body irradiation; UPN, unique patient number. transplant patient blood was unavailable, the patient's pretransplant genotype was identified by preparing DNA as above from fibroblasts cultured from skin biopsy specimens. Fibroblasts were cultured in RPMI-1640 (Gibco Laboratories, Grand Island, NY), 20\% fetal calf serum (Gibco Laboratories), streptomycin/penicillin, and 1\% L-glutamine, grown to confluence in tissue culture flasks (Corning Glass Works, Corning, NY), treated with $0.25 \%$ trypsin (Gibco Laboratories), and expanded to 5-15 $\times 10^{6}$ cells. 2-16 $\mu \mathrm{g}$ of DNA were digested to completion with one of the following restriction endonucleases: $E c o R I$ (Boehringer-Manheim, Indianapolis, IN), BamHI (Bethesda Research Laboratories, Gaithersburg, MD), HinclI, TaqI, and Pstl (New England Biolabs, Beverly, MA) using the conditions recommended by the manufacturers. In selected cases DNA was doubly digested with PstI and $X b a I$ (Bethesda Research Laboratories) for examination with the phosphoglycerate kinase probe (PGK) (24) (Table II). DNA fragments were then fractionated by electrophoresis in 0.6 to $1.0 \%$ agarose gels and transferred to nitrocellulose filters (Schleicher and Schuell, Keene, NH) by the technique of Southern (30).

Hybridization with DNA probes. The panel of six probes and corresponding restriction enzymes used, the chromosomal localization, and the allelic frequencies are listed in Table II. For PGK, AT3, BIVS2, and E1.3 purified insert was used as probe, whereas for PDP34 and PAW101 intact plasmid was used. The probes were labeled by nick translation with ${ }^{32} \mathrm{P}$-deoxynucleotide triphosphates (New England Nuclear, Boston, MA, or Amersham Corp., Arlington Heights, IL) to sp act 1 to $5 \times 10^{8} \mathrm{dpm} / \mu \mathrm{g}$ of DNA. Nitrocellulose filters prepared as above were then hybridized with the appropriate ${ }^{32} \mathrm{P}$-labeled probe, washed, and examined by autoradiography as previously described (28).

Fractionation of cells posttransplantation. At varying times after transplantation, 10 to $50 \mathrm{~cm}^{3}$ of patient blood were collected, defibrinated by agitation with glass beads, and, when sufficient cells were 
Table II. Probe Panel

\begin{tabular}{lllll}
\hline $\begin{array}{l}\text { Probe } \\
\text { [Restriction } \\
\text { enzyme] }\end{array}$ & $\begin{array}{l}\text { Chromosome } \\
\text { localization }\end{array}$ & $\begin{array}{l}\text { Number } \\
\text { of } \\
\text { alleles }\end{array}$ & $\begin{array}{l}\text { Frequency of } \\
\text { most common } \\
\text { allele }\end{array}$ & Reference \\
\hline $\begin{array}{l}\text { PAW } 101 \\
\quad[\text { EcoRI] }\end{array}$ & 14 & $>8$ & 0.3 & 22 \\
$\begin{array}{l}\text { PDP34 } \\
\quad[\text { TaqI] }\end{array}$ & $\mathrm{X} / \mathrm{Y}$ & 3 & $\ddagger$ & 21 \\
$\begin{array}{l}\text { AT3 [PstI] } \\
\text { PGK [PstI] }\end{array}$ & $\mathrm{X}$ & 2 & 0.5 & 20 \\
$\begin{array}{c}\text { BIVS2 } \\
{[\text { BamHI] }}\end{array}$ & 11 & 2 & 0.6 & 24 \\
PE1.3 & & 2 & 0.7 & 18,26 \\
{$[$ HincII] } & 11 & 2 & 0.6 & 18,29 \\
\hline
\end{tabular}

Abbreviations: BIVS2, portion of beta globin gene; $\mathrm{pE} 1.3$, portion of epsilon globin gene.

* This probe detects a length polymorphism due to large variations in length of a specific segment of DNA. The other five probes all detect polymorphisms due to single nucleotide changes or small DNA rearrangements within a specific restriction enzyme recognition site.

$¥$ This probe detects different length fragments on the $X$ and $Y$ chromosome and thus is applicable to all opposite sex patient/donor pairs. The $X$ chromosome band is also polymorphic in size with a major allele frequency of 0.78 , further extending its applicability.

available, fractionated into granulocyte, T lymphocyte, B lymphocyte and monocyte-enriched populations. Granulocytes were prepared from the pellet after Ficoll-Hypaque centrifugation. A monocyte-enriched fraction was prepared from the mononuclear cells by plastic adherence. Nonadherent cells were fractionated into $\mathrm{T}$ and $\mathrm{B}$ lymphocyte enriched populations by reaction with neuraminidase (Sigma Chemical Co., St. Louis, MO) treated sheep erythrocytes (Flow Laboratories, McLean, VA) and separation into E-rosette positive ( $T$ cells) and E-rosette negative (B cells) by Ficoll-Hypaque centrifugation. Purity of cell fractions was assessed by light microscopy of Wright-Giemsa stained specimens. $T$ and $B$ cells were further evaluated by labeling with the monoclonal antibodies T11, MO2, and B1 (Coulter Electronics, Inc., Hialeah, FL), followed by fluorescein isothiocyanate (FITC) conjugated goat anti-mouse antibody and analyzed on a fluorescence activated cell sorter or analyzer (fluorescence activated cell sorter, FACS 440, or FACS Analyzer, Becton-Dickinson, Sunnyvale, CA). Purities ranged from 85 to $95 \%$ for granulocytes, 60 to $80 \%$ for monocytes and B cells, and $>90 \%$ for T-cells.

Posttransplant B lymphocytes from patients UPN $128 \mathrm{H}$ and UPN 087 were transformed with Epstein-Barr virus (EBV) (31) and amplified in culture. To further purify the $T$ cells of patient UPN $128 \mathrm{H}$, peripheral blood mononuclear cells were depleted of monocytes by plastic adherence, nonadherent cells were passed over a nylon wool column, and the eluted cells were labeled with FITC conjugated, pan $T$ cell monoclonal antibody, Leu 4 (Becton-Dickinson). The labeled cells were further purified by sorting on a FACS 440 gated on the $50 \%$ most fluorescent cells, to yield a population that was $>99 \%$ Leu 4 positive cells.

DNA was prepared from fractionated subsets, and cultured cells, and examined by restriction enzyme analysis and blot hybridization as described above. As few as $10^{6}$ cells yielded sufficient DNA for analysis.

\section{Results}

Classification of polymorphisms. Pretransplant patient and donor DNA samples were analyzed with the various probes listed in Table II. When analysis with a given probe detected two different patterns, one for the patient's genotype and a second for the donor's, which thus, allowed DNA of patient and donor to be clearly distinguished from each other, this was classified as an "informative" polymorphism. When the patterns were identical this was classified as "uninformative." If an informative polymorphism resulted from the presence of a band in patient DNA that was absent from donor DNA, such a probe would be optimal for detecting residual low levels of host origin cells following transplantation and this was classified as "maximally informative-patient." Similarly, a polymorphic probe which detected a unique band in donor not present in the patient was classified as "maximally informative-donor." Occasionally a polymorphic probe detected both a unique patient band and a unique donor band, and was then classified as "maximally informative-patient and donor." Two examples of informative polymorphisms are shown in Fig. 1. The results of screening of pretransplant patient and donor DNAs for informative polymorphisms are shown in Table III.

General applicability and sensitivity. Given the various allelic frequencies listed in Table II, an informative polymorphism should be identifiable in $>95 \%$ of patient donor pairs. When sufficient patient and donor DNA was available for analysis with the full probe panel, we detected at least one informative polymorphism in all 18 cases studied. A polymor-

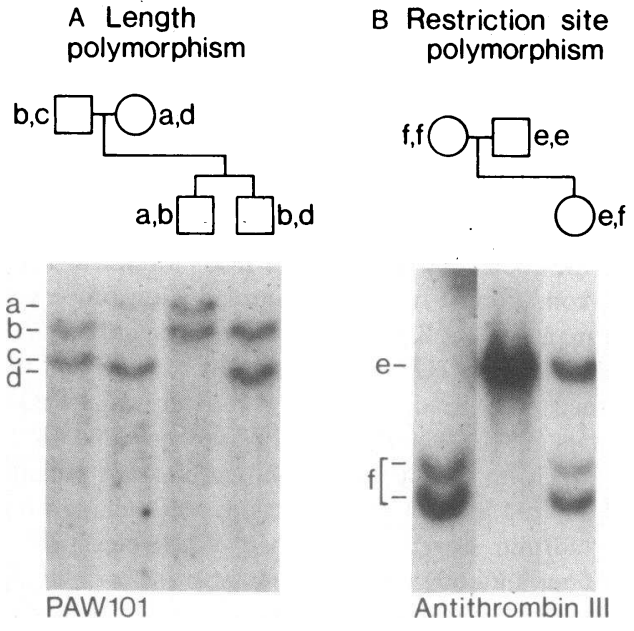

Figure 1. Examples of informative polymorphisms. $(A)$ A length polymorphism demonstrated by probe PAW101: each parent has two distinct alleles labeled a, b, c, and $\mathrm{d}(26.5,21,16$, and 15 kilobase [kb], in length, respectively; in the mother [lane 2], allele $a$ is artifactually lighter than allele $d$ due to slight partial degradation of that particular DNA specimen). The patient (UPN140-posttransplant analysis is shown in Fig. 2) and his donor brother have both inherited the same allele, b, from father but opposite alleles, a and d, from mother; the probe is thus maximally informative-patient and donor. $(B)$ Restriction site polymorphism of the antithrombin III gene: presence of the polymorphic PstI restriction site $(+)$ gives rise to two small bands of 5 and $5.5 \mathrm{~kb}$ (f), respectively. Absence of the site (-) gives rise to a single large $10.5-\mathrm{kb}$ band (e). Mother is homozygous $+/+$, father is homozygous $-/-$, and daughter (UPN $138 \mathrm{H})$ is an obligate heterozygote $(+/-)$. Father served as the bone marrow donor; the probe is thus maximally informative-patient. (Two small, invariant bands at $2.5 \mathrm{~kb}$ and $1.8 \mathrm{~kb}$, respectively, are also detected by the AT3 probe (20), but have been run past the bottom of the autoradiograph shown in this figure. They are still present on the longer autoradiograph shown in Fig. 4.) 
phism maximally informative for patient was found in 17 of 18 , and in all of these 17 the same, or a second probe was also maximally informative for donor (Table III).

To assess the sensitivity of this technique, a mixing experiment was performed, in which patient and donor DNA were mixed in varying proportions keeping the total constant, and then examined by restriction enzyme digestion and blot hybridization as outlined above. The minor population was still visible at levels as low as $1 \%$ of total DNA (Fig. 2). An equivalent level of sensitivity has been attained by Cleary et al. (32) using similar techniques to evaluate immunoglobulin gene rearrangements in mixed lymphoid populations.

Clinical utility. 18 cases have been examined after transplantation and these results are shown in Table $I .15$ of the 18 patients demonstrated complete engraftment. For illustration, the results from the study of patient UPN 140, are shown in Fig. 3. Patient and donor band patterns are clearly distinguishable using probe PAW 101 and are maximally informativepatient and donor. After transplantation all cell subsets show exclusively the donor pattern, thus documenting complete engraftment. Selected cases demonstrating the clinical utility of this general approach are discussed below.

Detection of mixed lymphohematopoietic chimerism. Three patients (UPN XXX, UPN 153, and UPN 128H) demonstrated mixed chimerism in their posttransplant peripheral blood cells UPN $\mathrm{XXX}$ is a 10 -yr-old male with aplastic anemia who received a bone marrow transplant from his HLA-identical brother in May 1982. In October 1983 marrow aplasia recurred with peripheral blood counts falling to: granulocytes, 450/ $\mathrm{mm}^{3}$; platelets, $16,000 / \mathrm{mm}^{3}$; and hemoglobin, $7.3 \mathrm{~g} / \mathrm{dl}$. Examination of DNA prepared from the patient's unfractionated peripheral leukocytes revealed mixed chimerism (Fig. 4). The patient was subsequently lost to follow-up.

UPN 153 is a 34 -yr-old white female with ALL in relapse who received a bone marrow transplant with her HLA-identical

Table III. Results of Screening with Probe Panel

\begin{tabular}{lllllll}
\hline UPN & PAW101 & PDP34 & AT3 & PGK & BIVS2 & PE1.3 \\
\hline XXX & B & - & P & N & N & N \\
075 & N & B & P & N & N & N \\
087 & N & B & N & - & - & - \\
$128 H$ & P & P & D & N & - & D \\
134 & N & - & D & B & D & N \\
136 & N & - & N & B & - & - \\
$138 H$ & N & D & P & N & - & - \\
139 & D & - & P & B & - & - \\
140 & B & - & N & N & N & N \\
144 & N & P & D & D & N & N \\
145 & P & B & N & N & P & N \\
146 & D & - & N & N & N & D \\
$147 H$ & D & P & P & N & N & D \\
149 & P & - & D & N & - & - \\
150 & D & P & P & N & - & - \\
151 & B & D & N & N & - & - \\
152 & D & B & P & D & - & - \\
153 & B & D & P & N & - & - \\
\hline
\end{tabular}

Abbreviations: B, maximally informative-both patient and donor; $D$, maximally informative-donor; $N$, uninformative; $P$, maximally informative-patient; -, not done.

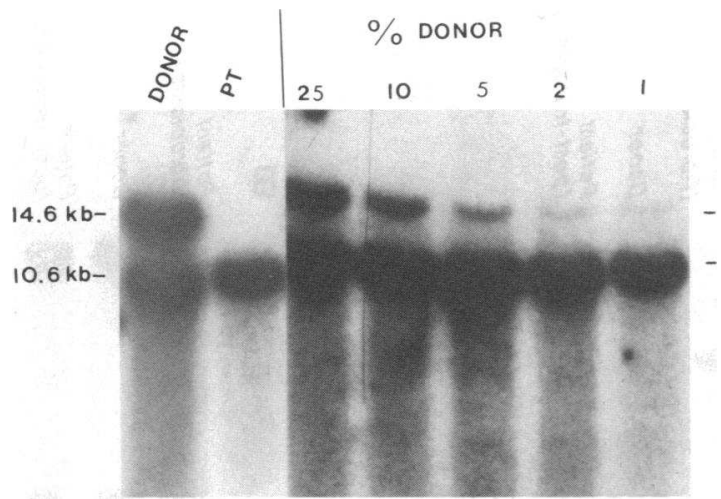

Figure 2. Mixing experiment to assess sensitivity. Donor and patient (PT) DNA samples were mixed in varying proportions keeping the total constant, and then examined by blot hybridization analysis using probe PDP34. Lane 1, donor DNA; lane 2, patient DNA; lanes 3-7, Mixtures with decreasing proportions of donor DNA from 25\% to $1 \%$. The donor shows both a $14.6-\mathrm{kb}$ band and a $10.6-\mathrm{kb}$ band. The patient shows just a 10.6-kb band. In this case, the presence of the 14.6-kb band is thus specific for donor DNA (maximally informative-donor). The donor-specific 14.6-kb band can still be detected at the $1 \%$ level (lane 7). Mixing experiments were repeated a number of times using probes PAW101 and AT3 as well as PDP34, and mixed DNA could be detected at the $5 \%$ level consistently, and at levels as low as $1 \%$ in some experiments.

brother as donor. Reconstitution of peripheral blood counts occurred rapidly, and DNA analysis on days 25 and 45 revealed mixed origin for circulating granulocytes, $T$ cells, $B$ cells, and monocytes with the majority of cells in all four subsets being of donor origin. At neither time could circulating leukemic lymphoblasts be demonstrated. These findings of mixed hematopoietic chimerism were confirmed by cytogenetic analysis of the patient's bone marrow, which revealed mixed host (XX) and donor (XY) metaphases. The patient's leukemia subsequently relapsed and DNA analysis on day 94 demonstrated that the blasts were of donor origin (data not shown).

UPN $128 \mathrm{H}$ is a 15 -mo-old male with SCIDS who received a bone marrow transplant with his mother as donor. Analysis of his posttransplant leukocyte DNA is shown in Fig. 5. Consistent with previous reports of marrow reconstitution following transplantation in this syndrome (17), the $T$ cells were exclusively of donor origin, while the granulocytes and B cells were of patient origin.

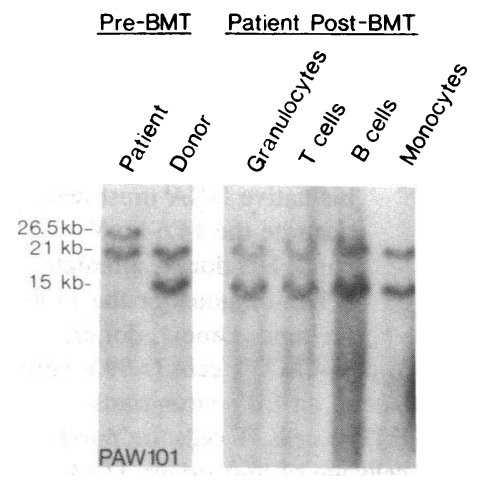

Figure 3. DNA analysis in patient UPN 140. DNA prepared from patient and donor before bone marrow transplant (pre-BMT) and from fractionated patient cells posttransplant (postBMT) were digested with EcoRI and examined by blot hybridization using probe PAW101. Patient and donor pretransplant band patterns were distinct and easily distinguishable; (maximally informative-patient and donor). Posttransplant cells all showed the donor pattern and thus were purely of donor origin. 


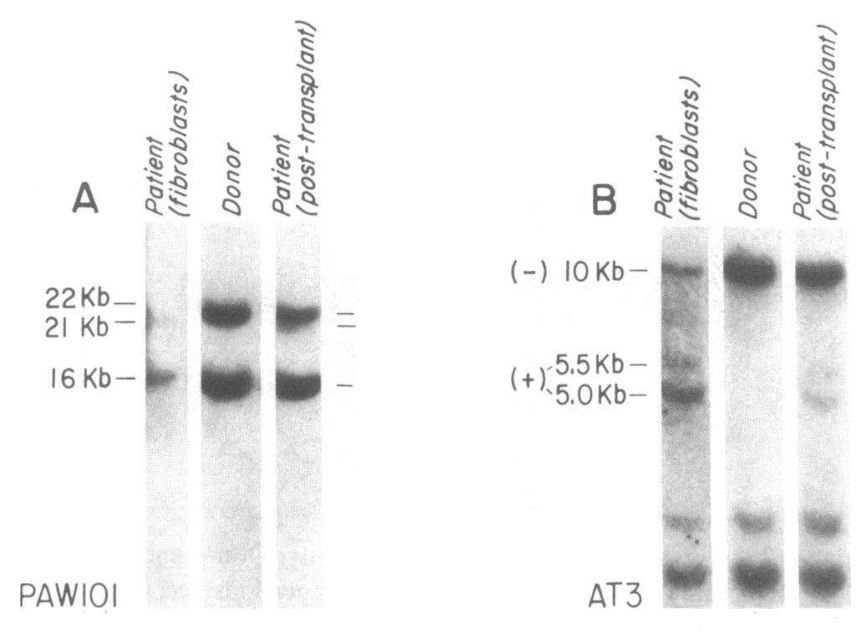

Figure 4. DNA analysis in patient UPN XXX. Two different probes demonstrate mixed peripheral blood chimerism. Lane 1, pretransplant patient DNA was unavailable, so DNA prepared from skin biopsy cultured fibroblasts was used to establish the patient's pretransplant genotype; lane 2, DNA from donor cells; lane 3, DNA prepared from patient's unfractionated peripheral blood cells collected $610 \mathrm{~d}$ after marrow transplantation. $(A)$ Analysis with probe PAW101 (maximally informative-patient and donor); patient and donor share a $16-\mathrm{kb}$ allele but differ at the second locus. The patient's posttransplant cells are mixed with both donor specific $(22 \mathrm{~kb})$ and host specific $(21 \mathrm{~kb})$ bands present. The difference in band intensity indicates a predominance of donor cells. $(B)$ Analysis with probe AT3 (maximally informative-patient); patient is $+/-$ and donor is $-1-$ (see legend, Fig. 1). The patient's posttransplant DNA shows faint bands at 5 and $5.5 \mathrm{~kb}$ representing the "+" allele (specific for the patient), thus confirming the results found with PAW101 (panel $A$ ). (The two small, unlabeled bands are invariant 2.5 and $1.8 \mathrm{~kb}$ fragments, respectively, which are also detected by the AT3 probe [20]).

Demonstration of engraftment. In three cases (UPN XXX, UPN 149, UPN 145) graft failure or rejection was suspected on clinical grounds. Patient UPN XXX was demonstrated to

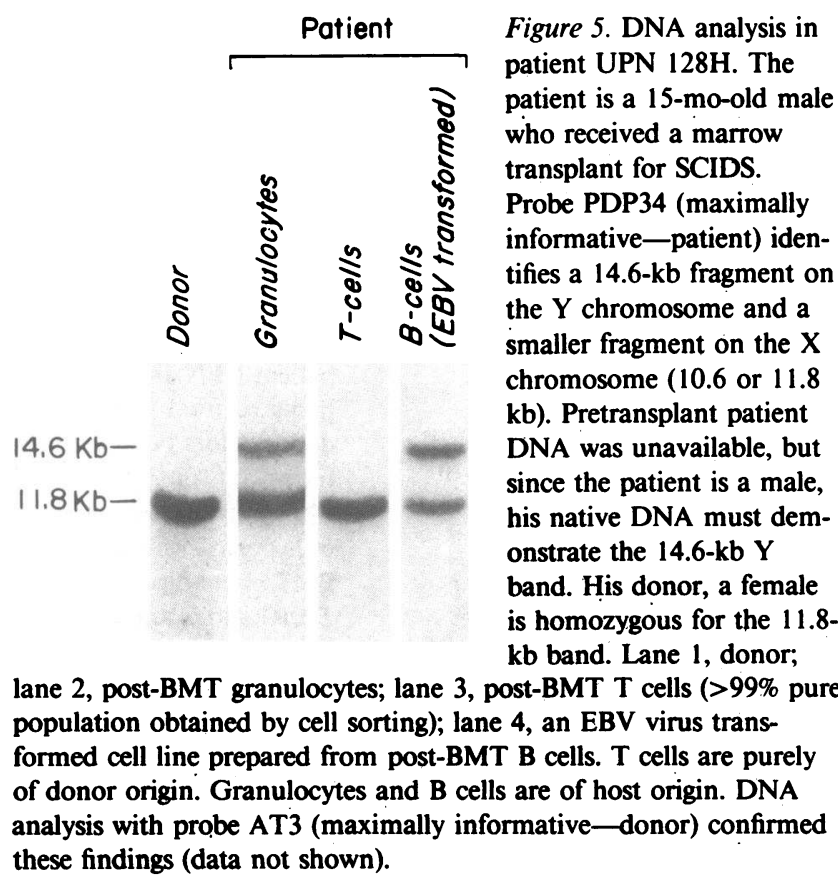

be a mixed chimera and is discussed above. Data from patient UPN 149 are shown in Fig. 6. The patient was a 27-yr-old female who received a bone marrow transplant for the treatment of acute myeloblastic leukemia. Clinical engraftment had occurred by day 33 , and was confirmed by DNA analysis. By day 65 , however, peripheral blood counts had fallen precipitously, suggesting loss of the graft. DNA polymorphism analysis demonstrated persistence of donor cells with no evidence for return of host elements. The leukocyte count subsequently began to rise, but the patient died of sepsis on day 79. Given the DNA analysis results, the leukopenia may have been secondary to sepsis or intercurrent drug therapy.

Patient UPN 145 received a bone marrow transplant for
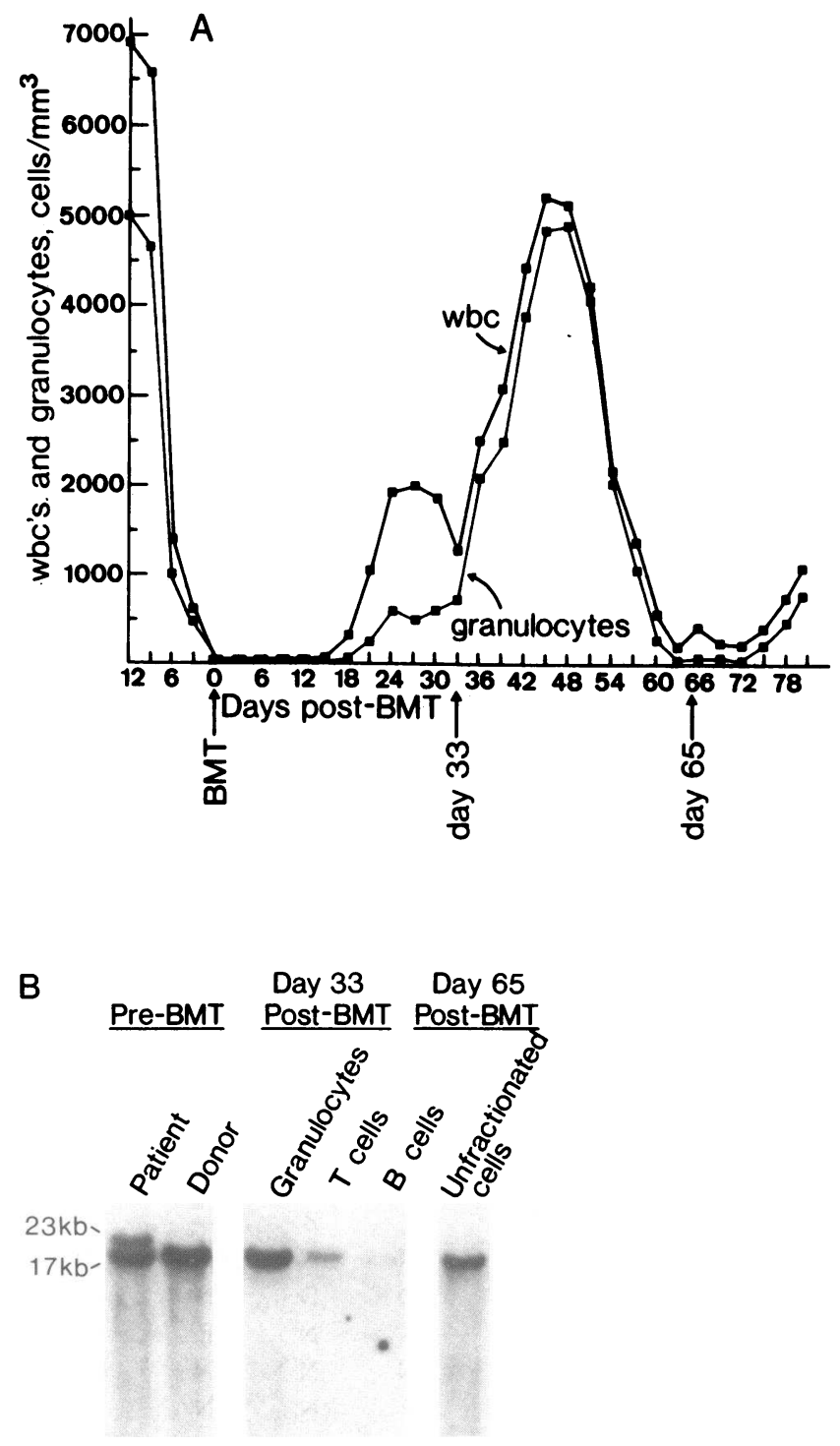

Figure 6. DNA analysis in patient UPN 149. $(A)$ The clinical course of the patient's leukocyte (wbc) and granulocyte count; $(B)$ DNA analysis at day 33 and day 65 using probe PAW 101 (maximally informative-patient); the patient's pretransplant (pre-BMT) genotype includes both a $23-$ and a $17-\mathrm{kb}$ fragment, whereas the donor is homozygous for the 17-kb fragment. At both time points post-BMT only the $17-\mathrm{kb}$ fragment (donor pattern) was detected, demonstrating continued complete engraftment. 
aplastic anemia. At $28 \mathrm{~d}$ after transplantation peripheral blood counts, particularly granulocytes, remained low, similar to pretransplant values and the occurrence of engraftment was initially questioned. Patient and donor could not be distinguished by HLA-typing or Y-body analysis. DNA polymorphism analysis demonstrated complete engraftment. The leukocyte count subsequently rose consistent with these findings.

In a fourth patient, UPN 087, anti-acetylcholine receptor antibody positive myasthenia gravis developed in association with chronic graft versus host disease (GVHD). Though the patient's pretransplant serum was also antibody positive, DNA analysis revealed complete engraftment with no evidence of residual host lymphocytes. The association of myasthenia gravis with chronic GVHD has recently been reported in one other patient (15).

\section{Discussion}

DNA sequence polymorphisms detectable in many regions of the human genome (18-24) have facilitated the study of inherited disease $(18-20,25,26)$. We report here the use of polymorphism analysis to establish the origin of cells following bone marrow transplantation.

The capacity to detect the change of a patient's hematopoietic and lymphoid cell compartments from host to donor origin after bone marrow transplantation is clinically useful in assessing both the occurrence and completeness of engraftment. The pattern of engraftment, particularly in the occasional case of mixed lympho-hematopoietic chimerism, is also of biologic interest and may add to our understanding of the mechanisms of graft rejection, GVHD, and the process of immune system reconstitution. The usual techniques used for this purpose show varying sensitivity and have been limited by the lack of general applicability to all patients and all cells in those patients. DNA sequence polymorphism analysis is applicable to over $95 \%$ of patients with the present panel of six probes, and with the addition of further probes could theoretically be applied to any patient/donor pair (excluding identical twins). Sensitivity is high, with small residual host (or donor) cell populations detectable at levels as low as $1 \%$ of the cells examined, which exceeds the purity of many cell fractionation techniques. Furthermore, any population of nucleated cells can be studied, regardless of mitotic phase.

Bone marrow transplantation performed following marrow ablative preparation with standard doses of TBI and high dose cyclophosphamide is generally followed by disappearance of all host lympho-hematopoietic elements and subsequent replacement by donor cells resulting in a "pure" chimeric state (1). After such a preparative regimen mixed lympho-hematopoietic chimerism is rarely encountered. Singer et al. (11) recently reported a single patient with stable mixed chimerism of myeloid cells (as judged by CFU-C colonies), marrow stromal cells and $\mathrm{T}$ lymphoid cells (by phytohemagglutinin stimulation). In 14 other cases similarly studied no CFU-C or marrow stromal cells of host origin were detected. Branch et al. (5) reported four patients with mixed hematopoietic chimerism following TBI and marrow transplantation. Host cells gradually replaced donor cells in two of these patients over time and may have represented gradual, late graft rejection. The higher incidence of mixed chimerism reported in this series may be related to differences in total body irradiation techniques $(5,11)$. In the recent experience with bone marrow transplantation for severe thalassemia, graft failure following initial engraftment has been frequent (33), and transient mixed chimerism has been noted (34), despite preparation with cyclophosphamide, and TBI and/or busulfan.

Following nonablative transplant preparation for aplastic anemia, failure of engraftment with subsequent autologous recovery may occur $(1,16)$, and mixed lympho-hematopoietic chimerism has been reported in a few cases $(14,16)$. SCIDS patients receiving no marrow ablative preparation frequently become mixed chimeras with hematopoietic cells still of host origin, T cells of donor origin, and B cells variably of donor or host origin (17). Mixed chimerism has also been encountered following transplantation for several other childhood immune disorders $(3,17)$.

In our study, using a more sensitive technique and studying all peripheral blood nucleated cells, we detected evidence of mixed hematopoietic or lymphoid chimerism in only 1 of 13 patients prepared with stem cell ablative therapy including either TBI or busulfan. In that mixed chimeric patient (UPN 153) posttransplant leukemic relapse occurred and was demonstrated to be of host origin. Prior to relapse host cells were detected among circulating mature granulocytes and mononuclear cells. The "stem cell ablative" preparation in this patient thus failed to eliminate normal progenitors, as well as leukemic stem cells. The presence of mixed lympho-hematopoietic chimerism following transplantation for leukemia, may indicate inadequate transplant preparation and a high risk for leukemic relapse.

Mixed lympho-hematopoietic chimerism was documented in two of the five patients who received less intensive preparative chemotherapy. Patient UPN $128 \mathrm{H}$, who had a pretransplant diagnosis of SCIDS and was prepared with cyclophosphamide and ATS, demonstrated mixed lymphoid chimerism, with T cells of donor origin and B cells and granulocytes of host origin. Interestingly, the patient has remained agammaglobulinemic after transplant, possibly reflecting the inability of engrafted donor $\mathrm{T}$ cells to cooperate with host $\mathrm{B}$ cells and accessory cells. In a second patient with SCIDS (UPN 138H) prepared with an ablative regimen including the stem cell toxin, busulfan, complete engraftment occurred with all cell lines becoming of donor origin. Of note, none of the three patients demonstrating mixed lympho-hematopoietic chimerism suffered from clinically significant GVHD. Similarly, where stated, the previously reported cases of stable mixed chimerism have also been free of major $\operatorname{GVHD}(3,11,14,16)$.

In addition to the study of mixed lympho-hematopoietic chimerism, we have demonstrated the clinical value of DNA analysis in cases of questionable engraftment or graft rejection following bone marrow transplantation. We have also shown that this approach is useful in the study of recurrent leukemia following bone marrow transplantation for distinguishing relapse of the original host leukemia from a second leukemia originating in donor cells. Although few patients have relapsed in donor cells (9), a more accurate assessment of the problem could be made by applying this technique to a larger number of cases. In addition to our case reported here, Minden and Messner have studied one case of recurrent leukemia also documenting host origin using DNA analysis (35). Rare cases of lymphoma arising in patients after marrow transplant can be studied similarly to determine the donor or host origin of the tumor. 
DNA analysis was used by Schubach et al. to demonstrate donor origin in one case of immunoblastic sarcoma arising following marrow transplantation (36). Another potential application of this method is the identification of the origin of noncirculating cells (e.g., tissue macrophages, marrow stromal cells) following transplantation. A few such cell populations have been studied by Y-body analysis in selected cases (8, $10,12)$.

In summary, we used molecular genetic techniques to study the origin of cells after bone marrow transplantation. This approach, based on the analysis of DNA polymorphisms is widely applicable, highly sensitive, and can be used to study any population of nucleated cells. Applications include the documentation of marrow engraftment, the detection and study of mixed lympho-hematopoietic chimerism, and the evaluation of posttransplant leukemic relapse.

\section{Acknowledgments}

We are indebted to Dr. R. White for the plasmid PAW101, to D. Page for the plasmid PDP34, to A. M. Michelson for the PGK CDNA probe, to Dr. K. A. Ault for helpful suggestions and assistance with the cell separations, to $K$. Baker for clinical assistance, and to Dr. D. G. Nathan and Dr. R. I. Handin for their continued support and encouragement.

This work was supported in part by grants from the National Institutes of Health, the Leukemia Society of America, the March of Dimes Birth Defects Foundation, the Olim Fund, the Malcolm Hecht Fund, and the Dyson Foundation.

\section{References}

1. Nathan, D. G., editor. 1983. Bone marrow transplantation. Clin. Haematol. Vol. 12.

2. Sparkes, M. C., M. L. Crist, R. S. Sparkes, R. P. Gale, S. A. Feig, and UCLA Transplantation Group. 1977. Gene markers in human bone marrow transplantation. Vox Sang. 33:202-205.

3. Parkman, R., J. Rappeport, R. Geha, J. Belli, R. Cassady, R. Levey, D. G. Nathan, and F. S. Rosen. 1978. Complete correction of the Wiskott-Aldrich syndrome by allogeneic bone-marrow transplantation. N. Engl. J. Med. 298:921-927.

4. Blume, K. G., K. J. Beutler, K. J. Bross, G. M. Schmidt, W. E. Spruce, and R. L. Teplitz. 1980. Genetic markers in human bone marrow transplantation. Am. J. Hum. Genet. 32:414-419.

5. Branch, D. R., M. T. Gallagher, S. J. Forman, K. J. Winkler, L. D. Petz, and K. G. Blume. 1982. Endogenous stem cell repopulation resulting in mixed hematopoietic chimerism following total body irradiation and marrow transplantation for acute leukemia. Transplantation. 34:226-228.

6. Reinherz, E. L., R. Geha, J. M. Rappeport, M. Wilson, A. C. Penta, R. E. Hussey, K. A. Fitzgerald, J. F. Daley, H. Levine, F. S. Rosen, and S. F. Schlossman. 1982. Reconstitution after transplantation with T-lymphocyte-depleted HLA haplotype-mismatched bone marrow for severe combined immunodeficiency. Proc. Natl. Acad. Sci. USA. 79:6047-6051.

7. Witherspoon, R. P., M. S. Schanfield, R. Storb, E. D. Thomas, and E. R. Giblett. 1978. Immunoglobulin production of donor origin after marrow transplantation for acute leukemia or aplastic anemia. Transplantation. 26:407-408.

8. Gale, R. P., R. S. Sparkes, and D. W. Golde. 1978. Bone marrow origin of hepatic macrophages (Kupffer cells) in humans. Nature (Lond.). 201:937-938.

9. Boyd, C. N., R. C. Ramberg, and E. D. Thomas. 1982. The incidence of recurrence of leukemia in donor cells after allogeneic bone marrow transplantation. Leuk. Res. 6:833-837.
10. Keating, A., J. W. Singer, P. D. Killen, G. E. Striker, A. C. Salo, J. Sanders, E. D. Thomas, D. Thorning, and P. J. Fialkow. 1982. Donor origin of the in vitro haematopoietic microenvironment after marrow transplantation in man. Nature (Lond.). 298:280-283.

11. Singer, J. W., A. Keating, R. Ramberg, R. McGuffin, J. E. Sanders, G. Sale, P. J. Fialkow, and E. D. Thomas. 1983. Long-term stable hematopoietic chimerism following marrow transplantation for acute lymphoblastic leukemia: A case report with in vitro marrow culture studies. Blood. 62:869-872.

12. Thomas, E. D., R. E. Ramberg, G. E. Sale, R. S. Sparkes, and D. W. Golde. 1976. Direct evidence for a bone marrow origin of the alveolar macrophage in man. Science (Wash. DC). 192:1016-1018.

13. Borgaonkar, D. S., W. B. Bias, B. M. Sroka, J. R. Hutchinson, and G. W. Santos. 1974. Identification of graft and host cells in bone marrow transplants by the quinacrine banding technique of chromosome identification. Acta Cytol. 18:263-267.

14. Grossbard, E. B., T. J. Garrett, L. Ratner, R. A. Good, R. J. O'Reilly, and R. S. K. Chaganti. 1979. Alteration in lymphoid chimerism associated with cytomegalovirus infection after bone marrow transplantation. Transplantation. 28:253-255.

15. Smith, C. I. E., J. A. Aarli, P. Biberfeld, P. Bolme, B. Christensson, G. Gahrton, L. Hammarstrom, A. K. Lefvert, B. Lonnqvist, G. Matell, R. Pirskanen, O. Ringden, and E. Svanborg. 1983. Myasthenia gravis after bone-marrow transplantation: evidence for a donor origin. N. Engl. J. Med. 309:1565-1568.

16. Hows, J. M., S. Palmer, and E. C. Gordon-Smith. 1982. Use of cyclosporin $\mathrm{A}$ in allogeneic bone marrow transplantation for severe aplastic anemia. Transplantation. 33:382-386.

17. Rappeport, J. M., B. R. Smith, R. Parkman, and F. S. Rosen. 1983. Application of bone marrow transplantation in genetic diseases. Clin. Haematol. 12:755-773.

18. Orkin, S. H., S. E. Antonarakis, and H. H. Kazazian, Jr. 1983. Polymorphism and molecular pathology of the human beta-globin gene. Prog. Hematol. 13:49-73.

19. Caskey, C. T., and R. L. White, editors. 1983. Banbury report 14: Recombinant DNA applications to human disease. Cold Spring Harbor Laboratory, Cold Spring Harbor, ME. 1-356.

20. Prochownik, E. V., S. Antonarakis, K. A. Bauer, R. D. Rosenberg, E. R. Fearon, and S. H. Orkin. 1983. Molecular heterogeneity of inherited antithrombin III deficiency. N. Engl. J. Med. 308:15491552.

21. Page, D., B. De Martinville, D. Barker, A. Wyman, R. White, U. Francke, and D. Botstein. 1982. Single-copy sequence hybridizes to polymorphic and homologous loci on human $\mathrm{X}$ and $\mathrm{Y}$ chromosomes. Proc. Natl. Acad. Sci. USA. 79:5352-5356.

22. Wyman, A. R., and R. White. 1980. A highly polymorphic locus in human DNA. Proc. Natl. Acad. Sci. USA. 77:6754-6758.

23. Bell, G. I., J. H. Karam, and W. J. Rutter. 1981. Polymorphic DNA region adjacent to the $5^{\prime}$ end of the human insulin gene. Proc. Natl. Acad. Sci. USA. 78:5759-5763.

24. Hutz, M. H., A. M. Michelson, S. E. Antonarakis, S. H. Orkin, and H. H. Kazazian, Jr. 1984. Restriction site polymorphism in the phosphoglycerate kinase gene on the $\mathrm{X}$ chromosome. Hum. Genet. 66:217-219.

25. Boehm, C. D., S. E. Antonarakis, J. A. Phillips III, G. Stetten, and H. H. Kazazian, Jr. 1983. Prenatal diagnosis using DNA polymorphisms: report on 95 pregnancies at risk for sickle-cell disease or beta thalassemia. N. Engl. J. Med. 308:1054-1058.

26. Kan, Y. W., K. Y. Lee, M. Furbetta, A. Angius, and A. Cao. 1980. Polymorphism of DNA sequence in the beta-globin gene region: application to prenatal diagnosis of beta $^{0}$ thalassemia in Sardinia. $N$. Engl. J. Med. 302:185-188.

27. Parkman, R., J. M. Rappeport, B. Camitta, R. Levey, and D. G. Nathan. 1978. Successful use of multiagent immunosuppression for the bone marrow transplantation of sensitized patients. Blood. 52:1163-1169.

28. Orkin, S. H., B. P. Alter, C. Altay, M. J. Mahoney, H. Lazarus, J. C. Hobbins, and D. G. Nathan. 1978. Application of endonuclease 
mapping to the analysis and prenatal diagnosis of thalassemias caused by globin-gene depletion. N. Engl. J. Med. 299:166-172.

29. Antonarakis, S. E., C. D. Boehm, P. J. V. Giardina, and H. H. Kazazian, Jr. 1982. Nonrandom association of polymorphic restriction sites in the beta-globin gene cluster. Proc. Natl. Acad. Sci. USA. 79:137-141.

30. Southern, E. M. 1975. Detection of specific sequences among DNA fragments separated by gel electrophoresis. J. Mol. Biol. 98:503517.

31. Miller, G., and L. Lipman. 1973. Release of infective EpsteinBarr virus by transformed marmoset leukocytes. Proc. Natl. Acad. Sci. USA. 70:190-194.

32. Cleary, M. L., J. Chao, R. Warnke, and J. Sklar. 1984. Immunoglobulin gene rearrangement as a diagnostic criterion of $\mathrm{B}$ cell lymphoma. Proc. Natl. Acad. Sci. USA. 81:593-597.
33. Lucarelli, G., T. Izzi, P. Polchi, M. Manna, F. Agostinelli, C. Delfini, M. Galimberti, A. Porcellini, L. Moretti, A. Manna, G. Sparaventi, M. Andreani, and A. Filippetti. 1983. Bone marrow transplantation in thalassemia. Exp. Hematol. 11(Suppl. 13):101-103.

34. Thomas, E. D., C. D. Buckner, J. E. Sanders, T. Papayannopoulou, C. Borgna-Pignatti, P. De Stefano, K. M. Sullivan, R. A. Clift, and R. Storb. 1982. Marrow transplantation for thalassemia. Lancet. II:227-229.

35. Minden, M. D., and H. A. Messner. 1983. Origin of hemopoietic cells in bone marrow transplantation using restriction fragment length polymorphisms (RFLP). Blood. 62(Suppl. 1):225a. (Abstr.)

36. Schubach, W. H., R. Hackman, P. E. Neiman, G. Miller, and E. D. Thomas. 1982. A monoclonal immunoblastic sarcoma in donor cells bearing Epstein-Barr virus genomes following allogeneic marrow grafting for acute lymphoblastic leukemia. Blood. 60:180-187. 